\title{
Provision of pharmaceutical care by community pharmacists across Europe: Is it developing and spreading?
}

Filipa A. Costa RPharm, MSc, $\mathrm{PhD}^{1,2,3}$ | Claire Scullin BSc, MSc, $\mathrm{PhD}^{4}$ (1) |

Ghaith Al-Taani BSc, MSc, $\mathrm{PhD}^{5}$ | Ahmed F. Hawwa BSc, $\mathrm{PhD}^{6}$ ।

Claire Anderson B Pharm, $\mathrm{PhD}^{7}$ | Zinaida Bezverhni PhD, $\mathrm{MPH}^{8}$ ।

Zahida Binakaj M.Sci. Pharm ${ }^{9}$ | Maria Cordina B. Pharm (Hons) (Melit.) PhD (QUB) ${ }^{10}$ ।

Veerle Foulon $\mathrm{PhD}^{11}$ | Borja Garcia de Bikuña MSc (Pharm), $\mathrm{PhD}^{12}$ ।

Han de Gier PharmD, PhD $^{13}$ | Anne Gerd Granås MSc (Pharm), PhD $^{14}$ |

Olga Grinstova PhD, $\mathrm{MPH}^{15}$ | Nina Griese-Mammen B. Pharm, $\mathrm{PhD}^{16}$ |

Jonas Grincevicius PhD RPh ${ }^{17}$ | Svitrigaile Grinceviciene PhD, LL.M. MD ${ }^{18}$ |

Susanne Kaae MSc (Pharm) $\mathrm{PhD}^{19}$ | Loreta Kubiliene PhD, $\mathrm{RPh}^{20}$ ।

Eduardo L. Mariño MSc (Pharm), $\mathrm{PhD}^{21}$ | Silvia Martins MSc ${ }^{22,23}$ |

Pilar Modamio MSc (Pharm), PhD $^{24}$ | Giancarlo Nadin PhD ${ }^{25}$ |

Lotte Stig Nørgaard MSc (Pharm), PhD ${ }^{19}$ | Emina Obarcanin PharmD, PhD ${ }^{26}$ |

Ivana Tadic PhD ${ }^{27}$ | Ljiljana Tasic PhD ${ }^{28}$ | James C. McElnay BSc (Pharm), PhD ${ }^{29}$ |

Kurt E. Hersberger MSc, PhD ${ }^{30}$ | Tommy Westerlund MSc (Pharm), MSc, PhD ${ }^{31,32}$

\footnotetext{
${ }^{1}$ Assistant Professor, Portuguese Pharmaceutical Society (PPS), Instituto Superior de Ciências da Saúde (ISCSEM), Lisbon, Portugal

${ }^{2}$ Researcher, Portuguese Pharmaceutical Society (PPS), Instituto Superior de Ciências da Saúde (ISCSEM), Lisbon, Portugal

${ }^{3}$ Consultant for Professional Strategic Planning, Portuguese Pharmaceutical Society (PPS), Instituto Superior de Ciências da Saúde (ISCSEM), Lisbon, Portugal

${ }^{4}$ Research Fellow, Clinical and Practice Research Group, School of Pharmacy, Medical Biology Centre, Queen's University Belfast, Belfast, UK

${ }^{5}$ Assistant Professor, Department of Pharmacy Practice, School of Pharmacy, Yarmouk University, Irbid, Jordan

${ }^{6}$ Visiting Researcher, Clinical and Practice Research Group, School of Pharmacy, Queen's University Belfast, Belfast, UK

${ }^{7}$ Professor of Social Pharmacy, School of Pharmacy, The University of Nottingham, Nottingham, UK

${ }^{8}$ Associate Professor, Department of Social Pharmacy, State University of Medicine and Pharmacy, "Nicolae Testemitanu", Chisinau, Republic of Moldova

${ }^{9}$ Pharmacist, Faculty of Pharmacy, University of Tuzla, Univerzitetska 8, 75000 Tuzla, Bosnia \& Herzegovina

${ }^{10}$ Professor, Department of Clinical Pharmacology and Therapeutics, Faculty of Medicine and Surgery, University of Malta, Msida, Malta

${ }^{11}$ Professor, Department Farmaceutische en Farmacologische Wetenschappen, Klinische Farmacologie en Farmacotherapie, O\&N II, KU Leuven, Leuven, Belgium

${ }^{12}$ Community Pharmacist, Foro de Atención Farmacéutica Farmacia Comunitaria, Consejo General de Colegios Oficiales de Farmacéuticos, Madrid, Spain

${ }^{13}$ Professor of Pharmaceutical Care, University of Groningen, Groningen, The Netherlands

${ }^{14}$ Professor, School of Pharmacy, University of Oslo, Oslo, Norway

${ }^{15}$ Lecturer, Department of Clinical Pharmacology and Clinical Pharmacy, National University of Pharmacy, Charkiv, Ukraine

${ }^{16} \mathrm{Head}$ of the Division Scientific Evaluation at ABDA, Department of Medicine, ABDA-Federal Union of German Associations of Pharmacists, Berlin, Germany

${ }^{17}$ Associate Professor, Department of Pathology, Forensic Medicine and Pharmacology, Vilnius University, Vilnius, Lithuania

${ }^{18}$ Obstetrics and Gynaecology, Institute of Biotechnology, Department of Biothermodynamics and Drug Design, Vilnius University, Vilnius, Lithuania

${ }^{19}$ Associate Professor, Faculty of Health and Medical Science, Department of Pharmacy, Section for Social and Clinical Pharmacy, Copenhagen University,

Copenhagen, Denmark

${ }^{20}$ Associate Professor, Department of Drug Technology and Social Pharmacy, Lithuanian University of Health Sciences, Kaunas, Lithuania
} 
${ }^{21}$ Professor, Clinical Pharmacy and Pharmacotherapy Unit, Department of Pharmacy and Pharmaceutical Technology and Physical Chemistry, Faculty of Pharmacy and Food Sciences, University of Barcelona, Barcelona, Spain

${ }^{22}$ Hospital Pharmacist, Hospital CUF-Descobertas, Lisbon, Portugal

${ }^{23}$ Researcher, Hospital CUF-Descobertas, Lisbon, Portugal

${ }^{24}$ Associate Professor, Clinical Pharmacy and Pharmacotherapy Unit, Department of Pharmacy and Pharmaceutical Technology and Physical Chemistry, Faculty of Pharmacy and Food Sciences, University of Barcelona, Barcelona, Spain

${ }^{25}$ Adjunct Professor of Marketing, Centrimark-Dept. of Economic and Business Management Sciences, Università Cattolica del Sacro Cuore, Milan, Italy

${ }^{26}$ Clinical Pharmacist \& Scientific Staff Member, Institute of Clinical Pharmacy and Pharmakotherapeutics, Heinrich-Heine Universität Düsseldorf, Düsseldorf, Germany

${ }^{27}$ Assistant Professor, Department for Social Pharmacy and Pharmaceutical Legislation, University of Belgrade-Faculty of Pharmacy, Belgrade, Serbia

${ }^{28}$ Professor, Department for Social Pharmacy and Pharmaceutical Legislation, University of Belgrade-Faculty of Pharmacy, Belgrade, Serbia

${ }^{29}$ Professor, Clinical and Practice Research Group, School of Pharmacy, Medical Biology Centre, Queen's University Belfast, Belfast, UK

${ }^{30}$ Professor, Pharmaceutical Care Research Group, University of Basel, Basel, Switzerland

${ }^{31}$ Associate Professor, Sahlgrenska Academy, Section for Epidemiology and Social Medicine (EPSO), University of Gothenburg, Gothenburg, Sweden

${ }^{32}$ Associate Professor, Faculty of Health and Society, Dept of Biomedical Science, Malmö University, Malmö, Sweden

\title{
Correspondence
}

James C McElnay, School of Pharmacy, Medical Biology Centre, Queen's University Belfast, 97 Lisburn Road, Belfast BT9 7BL, UK.

Email: j.mcelnay@qub.ac.uk

\begin{abstract}
Rationale, Aims, and Objectives: Pharmaceutical care involves patient-centred pharmacist activity to improve medicines management by patients. The implementation of this service in a comprehensive manner, however, requires considerable organisation and effort, and indeed, it is often not fully implemented in care settings.

The main objective was to assess how pharmaceutical care provision within community pharmacy has evolved over time in Europe.

Method: A cross-sectional questionnaire-based survey of community pharmacies, using a modified version of the Behavioural Pharmaceutical Care Scale (BPCS) was conducted in late 2012/early 2013 within 16 European countries and compared with an earlier assessment conducted in 2006.

Results: The provision of comprehensive pharmaceutical care has slightly improved in all European countries that participated in both editions of this survey $(n=8)$ with progress being made particularly in Denmark and Switzerland. Moreover, there was a wider country uptake, indicating spread of the concept. However, due to a number of limitations, the results should be interpreted with caution. Using combined data from participating countries, the provision of pharmaceutical care was positively correlated with the participation of the community pharmacists in patient-centred activities, routine use of pharmacy software with access to clinical data, participation in multidisciplinary team meetings, and having specialized education.
\end{abstract}

Conclusions: The present study demonstrated a slight evolution in self-reported provision of pharmaceutical care by community pharmacists across Europe, as measured by the BPCS. The slow progress suggests a range of barriers, which are preventing pharmacists moving beyond traditional roles. Support from professional bodies and more patient-centred community pharmacy contracts, including remuneration for pharmaceutical care services, are likely to be required if quicker progress is to be made in the future.

\section{KEYWORDS}

Europe, implementation, medication review, medicines use, pharmaceutical care, pharmacy services

\section{1 | INTRODUCTION}

Within the context of pharmacy practice, during the last 2 decades, increased attention has been focused on the change in the community pharmacist's role from product-focused to more patient-focused activities. With continued efforts to improve patient health outcomes, and

Anne Gerd Granås: Work carried out whilst at Oslo and Akershus University College.Silvia Martins: Work carried out whilst at Instituto Superior de Ciências da Saúde (ISCSEM). Centre for Interdisciplinary Research (CiiEM), Campus Universitário, Quinta da Granja, 2829-511 Caparica.Emina Obarcanin: Work carried out at Faculty of Pharmacy University of Tuzla, Bosnia Herzegovina. [Correction added on 17 August 2017, after first online publication: Co-author Jonas Grinceviciene should be Jonas Grincevicius.] in response to the challenge of a patient-focused approach, the concept of pharmaceutical care was developed in the United States ${ }^{1}$ and was quickly adopted as "good pharmacy practice" internationally. ${ }^{2}$

Delivery of pharmaceutical care has important demands on structure and process of the delivery of services in community pharmacies. ${ }^{3}$ Different countries, according to the country-specific practice culture and systems of health delivery, have adopted pharmaceutical care services in different forms that match the local situation needs and which take into account various barriers and facilitating factors. ${ }^{3}$ The concept of pharmaceutical care is complex and has continued to evolve over the years with many different definitions appearing in the literature. In an attempt to harmonize definitions, the board of 
the Pharmaceutical Care Network Europe (PCNE) reached a consensus on a PCNE definition of pharmaceutical care, stating that it "is the pharmacist's contribution to the care of individuals in order to optimise medicines use and improve health outcomes."

A number of barriers have been identified internationally, which have hindered the implementation of comprehensive pharmaceutical care programmes within community pharmacies, including limited time, lack of reimbursement for the extra time required to deliver the service, high work load, inadequate competency, and lack of commitment. ${ }^{5-8}$ To facilitate the implementation of pharmaceutical care in the community pharmacy setting, there is a need to build good relationships with general medical practitioners (GPs), to receive financial compensation for the service, to have the appropriate premises (eg, private counselling area), to have appropriate and sufficiently trained staff, to have a high degree of co-ordinated teamwork and an ability to receive external guidance. ${ }^{9}$ A conscious effort from individual pharmacists to deliver pharmaceutical care programmes and/or legislation that redefines the role the pharmacist is required to facilitate pharmaceutical care implementation. ${ }^{10}$

Although the effectiveness of pharmaceutical care delivery has been largely defined in the context of research studies, ${ }^{11}$ quantification of the service provided under everyday care conditions is important. A few studies describe the influence of the policy context in the implementation of services, ${ }^{12}$ while others focus on structural influences, such as the existence of software capable of uploading identified drug-related problems into a national database..$^{13}$ The usual method to assess the provision of pharmaceutical care deployed in a large number of pharmacies is by the use of survey methodology, using a validated data collection instrument. Survey methodology compromises much of the pharmacy practice research literature corpus; it is surprising, however, that only a relatively few studies have assessed the degree of provision of pharmaceutical care in community pharmacies. ${ }^{10,14-21}$

The main aim of the present study was to assess the current degree of provision of pharmaceutical care by community pharmacists across Europe and to determine whether the degree of implementation had changed since 2006.

\section{2 | METHODS}

The provision of pharmaceutical care by community pharmacists across Europe was assessed through the co-operation of the PCNE (www. pcne.org). Having achieved the agreement of PCNE members from different European countries to participate, data were collected from 16 countries (Bosnia, Denmark, England, Germany, Italy, Lithuania, Malta, Moldova, the Netherlands, Northern Ireland, Norway, Portugal, Serbia, Spain, Sweden, and Switzerland), with ethical approval being achieved as required by local regulation. Belgium and the Ukraine engaged with the initiative, but due to logistical reasons, data collection/validation was delayed and has not been included in the analysis.

\section{1 | Questionnaire/instrument}

A validated instrument, with 2 separate sections, was used. ${ }^{10,14} \mathrm{Sec}-$ tion A collected data on pharmacists' demographics and pharmacy services and layout. Section B evaluated the types of services provided to the last patients using the pharmacy (5 or 10) referring to a specific time period ( 2 or $6 \mathrm{wk}$ ) using vignettes from a slightly modified version of the Behavioural Pharmaceutical Care Scale (BPCS). The vignettes describe different situations, eg, dealing with a first prescription or repeat dispensing. The BPCS comprises 34 items, which contribute to 3 domains, direct patient care activities (DPCA), referral and consultation activities, and instrumental activities. This questionnaire has been previously used by researchers to assess the provision of pharmaceutical care by community pharmacists in Northern Ireland and then in a study across Europe. ${ }^{10,15}$ The questionnaires were distributed late 2012/early 2013, ie, the current survey is referred to throughout paper as 2013.

\section{2 | Data collection}

The study was coordinated by Queen's University Belfast and used PCNE to identify country coordinators. The country coordinators were responsible for determining the most effective manner to reach one pharmacist per pharmacy (ie, pharmacist most involved in patient care activities), and they were informed on the sample size considered representative of their country, considering a confidence interval of $95 \%$, a $3 \%$ error, and a prevalence of the phenomenon (provision of pharmaceutical care) ranging from $4.8 \%$ to $25 \%$, according to results from the previous study. ${ }^{10}$ In countries that had not participated in the previous round, the lowest prevalence was considered, unless a national study could be used as reference (eg, Spain). The method of distribution varied from country to country according to the available resources and research practice, ie, online, face-to-face, or via regular post. Most countries used an online survey method (Table 1).

\section{3 | Data entry and analysis}

Data entry was the responsibility of each country coordinator, guided by a standard operating procedure to ensure quality. ${ }^{22}$ Data obtained from the surveyed countries were uploaded into SPSS v19 for detailed statistical analysis and sent to the study coordinator. Standard statistical methodologies were used in the assessment of the provision of pharmaceutical care by community pharmacists. Descriptive statistics were used to summarize the data of all participating countries. Multiple pairwise comparisons were conducted to compare the total and BPCS dimension scores between the participating countries. A Bonferroni adjustment for multiple comparisons was conducted. Dimension and total BPCS scores were also compared between the countries that participated in both editions of the survey (2006 vs 2013), using the Wilcoxon test. ${ }^{10}$ Pharmacist and pharmacy characteristics were explored for their association with the total BPCS scores, using combined data from all participating countries. Multiple linear regression modelling was used to identify factors contributing to the level of implementation as determined by the BPCS score. Statistical significance was set at $P=.05$. As in previous research using the BPCS survey instrument, pharmacists who achieved a top quartile total BPCS score were categorized as providers of pharmaceutical care whereas pharmacists scoring in the bottom $25 \%$ were categorized as non-providers at the country level. Therefore, the cut-off values used varies across countries. 
TABLE 1 Response rate to 2013 Behavioural Pharmaceutical Care Scale survey administration across European countries

\begin{tabular}{|c|c|c|c|c|c|c|}
\hline Country & $\begin{array}{c}\text { Survey } \\
\text { methodology }\end{array}$ & $\begin{array}{c}\text { Number of existing } \\
\text { pharmacies }\end{array}$ & $\begin{array}{c}\text { Prevalence considered, }{ }^{a} \\
\%\end{array}$ & $\begin{array}{l}\text { Sample estimated } \\
\text { (n) }\end{array}$ & $\begin{array}{l}\text { Respondents } \\
\text { (n) }\end{array}$ & $\begin{array}{l}\text { Response } \\
\text { rate, \% }\end{array}$ \\
\hline Bosnia & Online & 100 & 4.8 & 66 & 99 & 99.0 \\
\hline Denmark & Online & 300 & 4.8 & 118 & 90 & 30.0 \\
\hline England & Online & $9225^{b}$ & 9.9 & 337 & 78 & 0.9 \\
\hline Germany & Online & 5968 & 21.5 & 643 & 722 & 12.1 \\
\hline Italy & Online & 17000 & 4.8 & 193 & 807 & 4.7 \\
\hline Malta & Postal & 213 & 11.6 & 143 & 83 & 39.0 \\
\hline Moldova & Online and postal & 400 & 4.8 & 131 & 315 & 78.8 \\
\hline Netherlands & Online & 1966 & 4.8 & 178 & 209 & 10.6 \\
\hline Northern Ireland & Postal & 549 & 25.0 & 326 & 150 & 27.3 \\
\hline Norway & Postal & 679 & 4.8 & 152 & 257 & 37.8 \\
\hline Sweden & Online & 1318 & 6.2 & 209 & 375 & 28.4 \\
\hline Switzerland & Online & 1757 & 22.4 & 522 & 390 & 22.2 \\
\hline
\end{tabular}

The prevalence value was obtained from results of the 2006 study. For those not participating in the 2006 study, the lowest level of implementation was used. bink to the online survey included in general pharmacy correspondence.

\section{3 | RESULTS}

\section{1 | Response rate and practice demographics}

In 11 countries, the sample reached surpassed the estimated representative sample size. Countries below the estimates were Denmark, England, Malta, Northern Ireland, and Switzerland. The response rate was considered too low for England to be valid, and England was therefore removed from the comparative analysis. The remaining countries were included in the comparative analysis; however, significant caution should be used in interpretation of the data due to possible unrepresentativeness of the respondent sample (Table 1).

The responding community pharmacists were more commonly ( $>50 \%$ ) females in all of the surveyed countries except Italy, the Netherlands, and Northern Ireland. Pharmacies had been instructed that the pharmacist with the most patient contact should take the lead in the survey, resulting in $>60 \%$ of responding pharmacists with more than 5 years of experience in community pharmacy in all surveyed countries.

\section{2 | Variations in pharmacy practice settings}

A wide distribution in the type and location of the pharmacies was noted in the surveyed countries. Pharmacy type ranged from $100 \%$ independent in Denmark, Germany, and Spain to $89.6 \%$ large multiple in Serbia and $\mathbf{9 0 . 3 \%}$ in Norway (Table 2).

It was common for one full-time equivalent (FTE) pharmacist to work in each pharmacy in England, Malta, the Netherlands, and Northern Ireland whereas the remainder of the surveyed countries had 2 or more pharmacists working in each pharmacy. In Sweden, $46 \%$ of the respondents were "prescriptionists," holding a BSc (Pharm) degree, while the remainder were pharmacists with an MSc (Pharm) degree. In all of the surveyed countries (except in Denmark, Germany, Norway, Serbia, and Switzerland), there was, on average, 2 or fewer dispensing support staff working in the pharmacies. In half of the surveyed countries, the pharmacies on average dispensed $>200$ prescription items per day, while <200 items per day were dispensed in Bosnia, Germany, Italy, Lithuania, Malta, Moldova, Spain, and Switzerland. A weak but significant correlation was noted between the number of prescription items dispensed per day and the number of FTE pharmacists (Spearman rho $=0.292 ; P<.001)$ and FTE dispensing staff (Spearman rho $=0.328 ; P<.001)$.

In all surveyed countries, apart from the Netherlands, less than $50 \%$ of respondent pharmacists participated in multidisciplinary team meetings. Private consultation areas were present to a large extent in pharmacies in all of the surveyed countries, with the exception of Lithuania, Moldova, and Serbia. Most of the surveyed countries, except in Lithuania, Moldova, and Serbia, routinely used customized pharmacy software to assist with the dispensing process. The extent of the use of software to check clinical data, drug interactions, and contraindications by community pharmacists varied across the surveyed pharmacies. In all the surveyed countries, fewer than 50\% of responding pharmacists indicated that patient-level clinical data were available via a shared database with the hospital or the GP. More than $25 \%$ of responding pharmacists, however, judged that these clinical data were easily accessed if required. Responding pharmacists participated in patient-centred services such as health screening, patient monitoring, medication review, and health promotion/education to a high extent in most surveyed countries, except for Moldova. A low participation was also found for Lithuania, Sweden, and Denmark, with the exception made to medication review. Italy was actively engaged in 2 of these services (health promotion and education) but very little in the other services. It is also worth pointing out that in the Netherlands, over $90 \%$ of responding pharmacists stated that they were engaged in medication review. Medication review was the most cited service by 3 of the surveyed countries: the Netherlands, Germany, and Denmark (Table 2). 


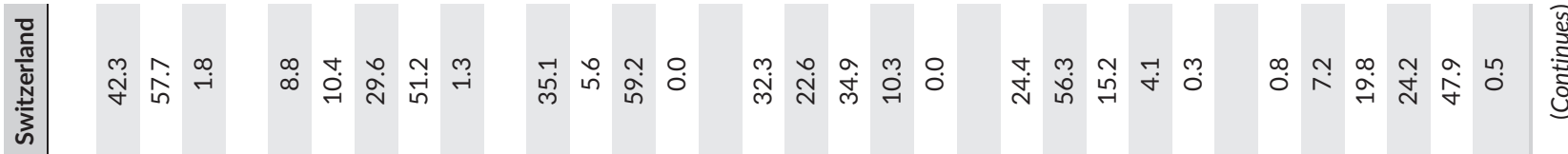

峛

जी ஸ્m

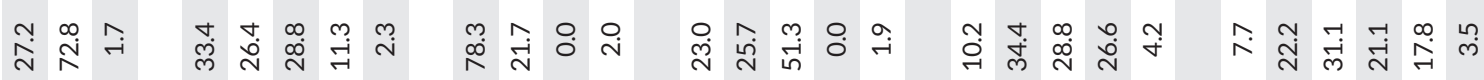

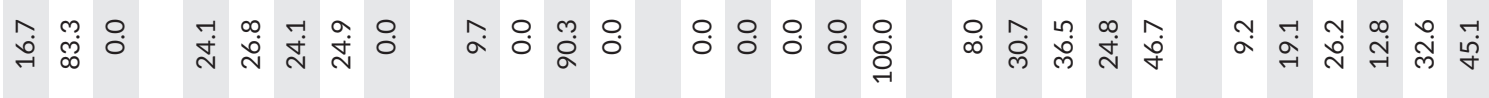

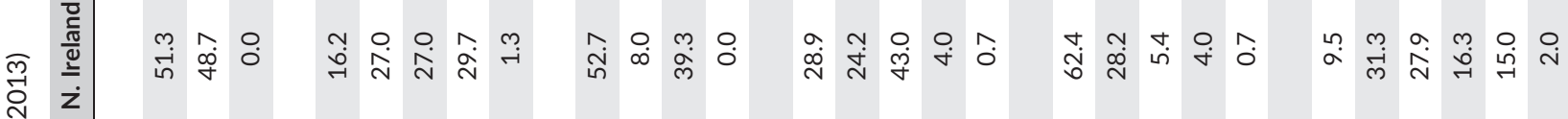

ம்

ஓ নু

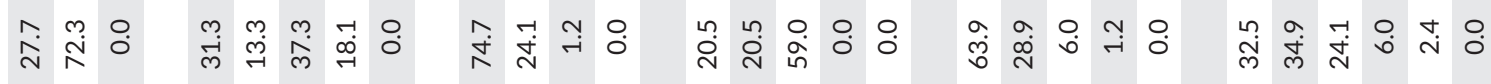

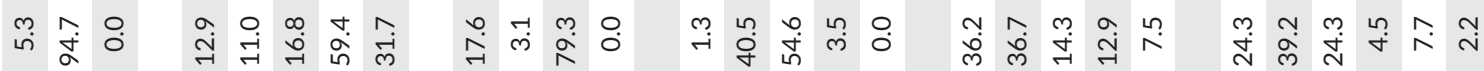

तु่

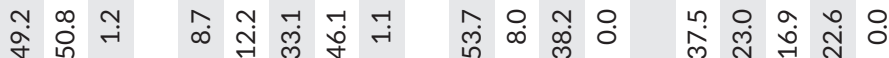

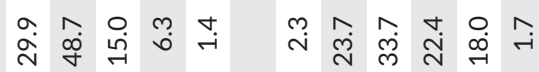

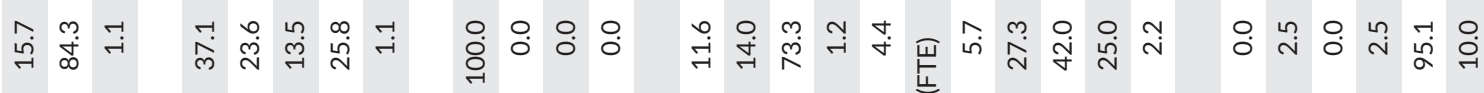
竞 
|

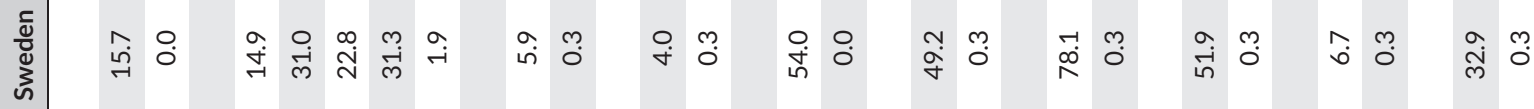

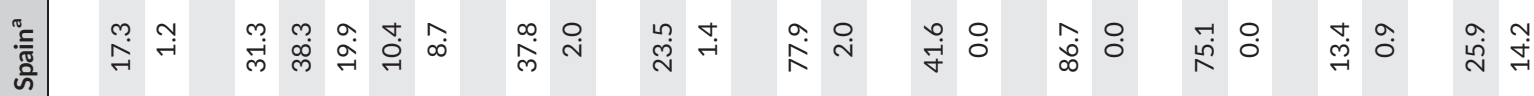

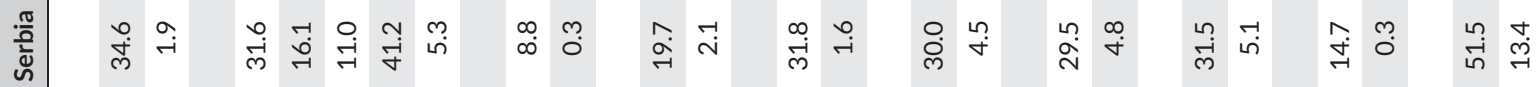

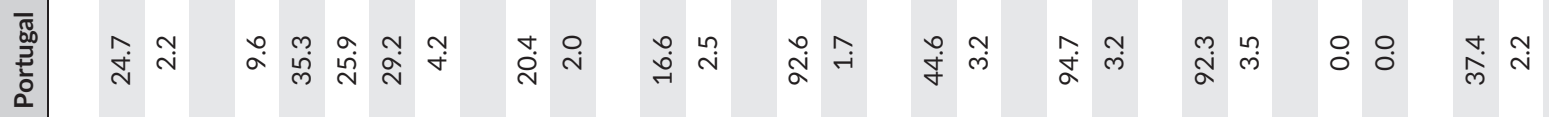

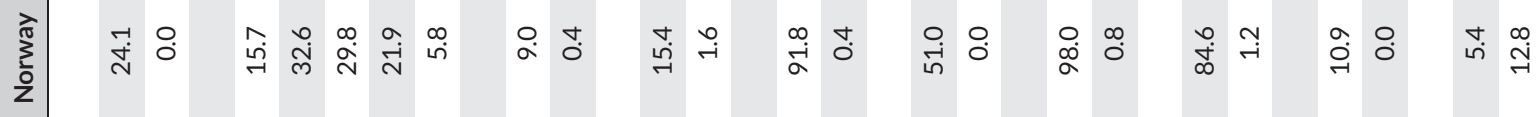

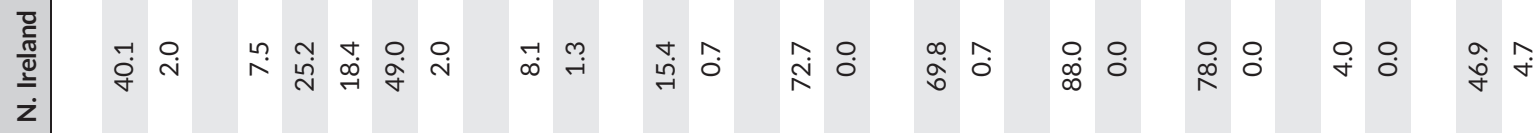

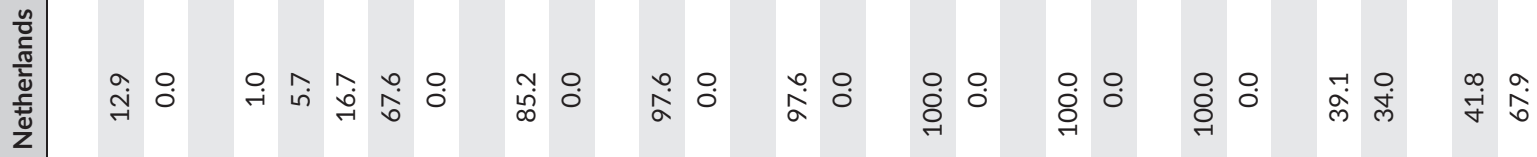

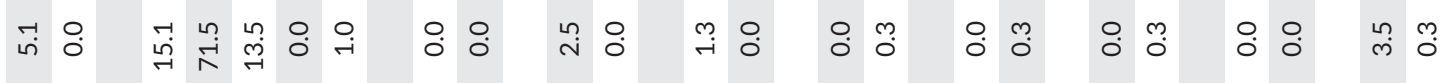

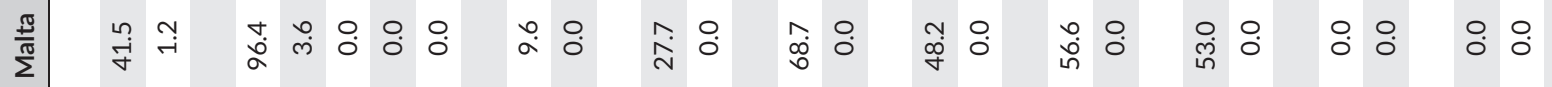

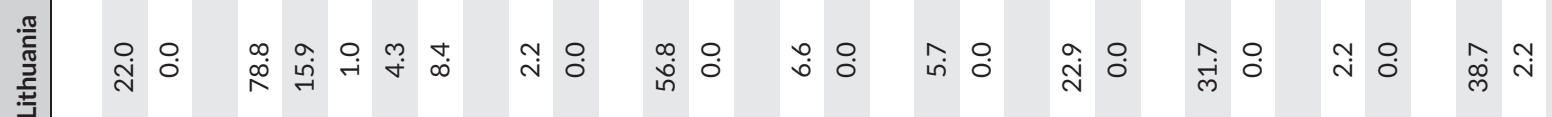

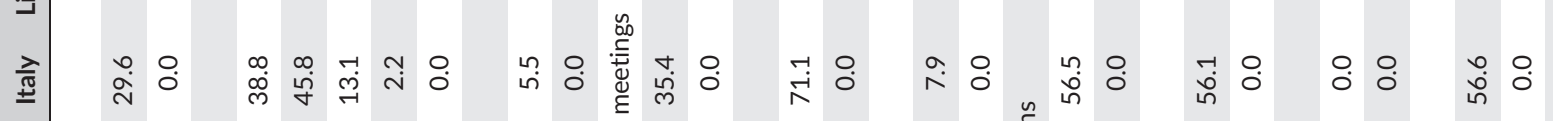

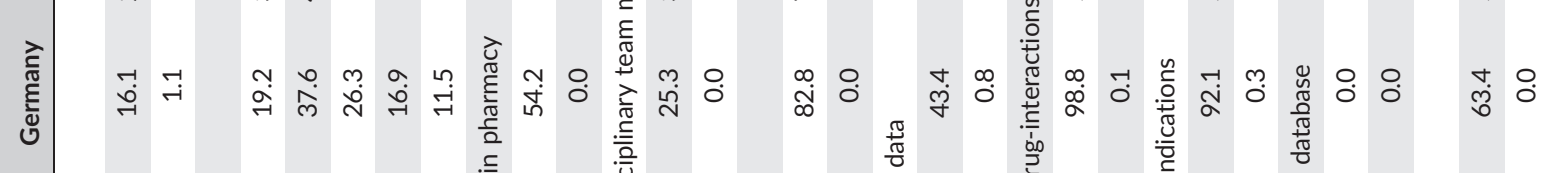

竎

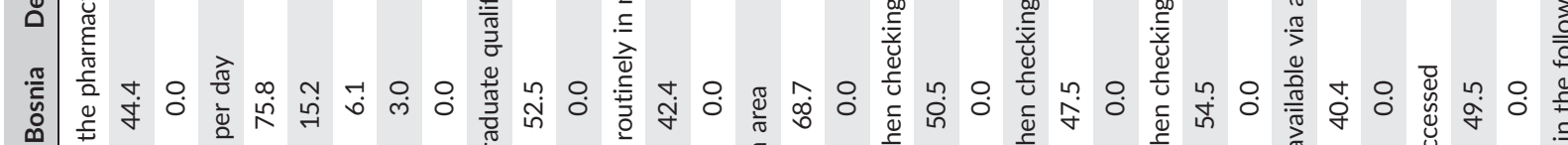

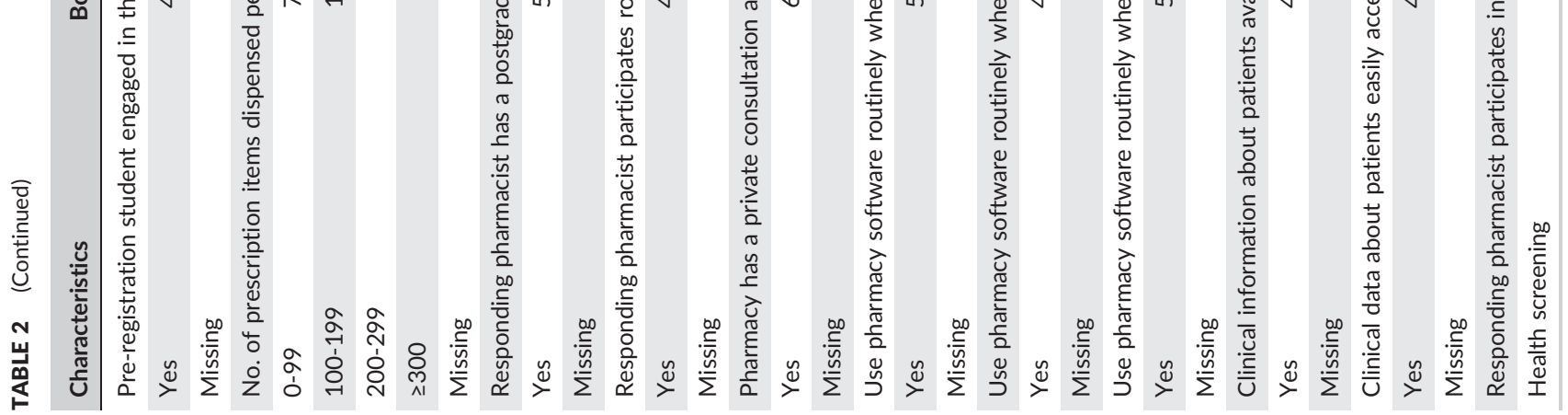




\section{3 | BPCS scores}

The BPCS scores for each country are presented in Table 3. In the Netherlands survey, one of the items in the questionnaire from the referral and consultation dimension was inadvertently missed out; it was therefore not possible to calculate this dimension score and the total BPCS score for this country.

The highest mean total BPCS scores were achieved by pharmacists from Switzerland (82.7/160) and Spain (80.2/160). Total BPCS scores achieved in Switzerland were significantly higher $(P<.05)$ than in the other surveyed countries. Moldova's pharmacists scored the lowest mean total BPCS score (47.0/160). Graphical representations of the total and BPCS scores are presented in Figure 1. Lines have been inserted in the figure at the BPCS scores of 50 and 70, which helps highlight the stage of evolution in each country towards comprehensive pharmaceutical care provision.

Switzerland also achieved a high mean score for the DPCA dimension (41.5/85), with the Netherlands, Portugal, and Germany also scoring highly in this dimension (34.8, 34.7, and 33.0/85). The lowest mean DPCA dimension score was achieved in Moldova (13.4/85).

The highest mean referral and consultation activity dimension score was noted in Denmark and Spain (28.7 and 28.6/40), while the lowest score in this dimension was achieved in Moldova (16.3/40). Referral and consultation activity scores achieved in Spain were significantly higher $(P<.05)$ than in other countries.

The highest mean instrumental activity dimension score was noted in the Netherlands (26.6/35), while again the lowest score was achieved in Moldova (17.3/35). Instrumental activity scores achieved in the Netherlands were significantly $(P<.05)$ higher than in the other surveyed countries.

\section{4 | Providers and non-providers of pharmaceutical care}

In accordance with the original questionnaire designers, ${ }^{14}$ at country level, pharmacies achieving BPCS scores within the top $25 \%$ were considered providers of pharmaceutical care while those in the bottom $25 \%$ were considered non-providers (Table 4).

\subsection{Evolution of pharmaceutical care provision over time}

Total BPCS scores remained static or evolved positively, although in some cases marginally, over time for the countries that engaged (between the 2006 and 2013 surveys), ie, Denmark, Germany, Malta, Northern Ireland, Portugal, Sweden, and Switzerland. Denmark and Switzerland were the only 2 countries that achieved a step change in the total score achieved.

Direct patient care activity scores obtained in the 2013 study were significantly higher $(P<.05)$ than those achieved in the 2006 survey. Referral and consultation dimension scores in the present study were, however, significantly lower $(P<.05)$ than those obtained in the 2006 survey. No significant differences between 2006 and 2013 data were noted for the instrumental activity scores (Table 5). 
TABLE 3 Respondents' scores for the modified BPCS across different European countries (2013)

\begin{tabular}{|c|c|c|c|c|}
\hline Country & $\begin{array}{l}\text { Total BPCS Score } \\
\text { (Mean } \pm \text { SD) }\end{array}$ & $\begin{array}{l}\text { Direct Patient Care Activities } \\
\text { (Mean } \pm \text { SD) }\end{array}$ & $\begin{array}{l}\text { Referral and Consultation Activities } \\
\qquad(\text { Mean } \pm \text { SD) }\end{array}$ & $\begin{array}{l}\text { Instrumental Activities } \\
\text { (Mean } \pm \text { SD) }\end{array}$ \\
\hline Bosnia & $78.0 \pm 10.6$ & $29.4 \pm 8.5$ & $24.3 \pm 2.5$ & $24.3 \pm 2.2$ \\
\hline Denmark & $75.6 \pm 12.9$ & $26.3 \pm 12.8$ & $28.7 \pm 5.1$ & $20.8 \pm 2.7$ \\
\hline Germany & $72.1 \pm 22.7$ & $33.0 \pm 16.5$ & $20.4 \pm 5.5$ & $18.9 \pm 3.9$ \\
\hline Italy & $57.3 \pm 22.4$ & $19.6 \pm 14.8$ & $17.0 \pm 5.7$ & $20.8 \pm 6.0$ \\
\hline Lithuania & $60.4 \pm 20.8$ & $23.1 \pm 14.9$ & $16.7 \pm 5.6$ & $20.6 \pm 4.9$ \\
\hline Malta & $75.6 \pm 22.1$ & $29.3 \pm 16.0$ & $22.6 \pm 6.2$ & $23.7 \pm 4.2$ \\
\hline Moldova & $47.0 \pm 2.1$ & $13.4 \pm 1.4$ & $16.3 \pm 1.3$ & $17.3 \pm 2.1$ \\
\hline The Netherlands ${ }^{a}$ & & $34.8 \pm 3$ & & $26.6 \pm 3.3$ \\
\hline N. Ireland & $73.8 \pm 20.7$ & $29.2 \pm 14.8$ & $20.2 \pm 5.2$ & $24.1 \pm 4.0$ \\
\hline Norway & $66.7 \pm 20.1$ & $25.1 \pm 15.2$ & $19.3 \pm 4.6$ & $22.5 \pm 4.2$ \\
\hline Portugal & $77.3 \pm 21.5$ & $34.8 \pm 15.1$ & $20.5 \pm 5.5$ & $22.2 \pm 4.7$ \\
\hline Serbia & $77.5 \pm 25.5$ & $32.1 \pm 16.8$ & $21.5 \pm 6.6$ & $24.0 \pm 4.5$ \\
\hline Spain & $80.2 \pm 14.8$ & $30.8 \pm 18.3$ & $28.6 \pm 5.7$ & $20.4 \pm 4.9$ \\
\hline Sweden & $63.2 \pm 15.7$ & $24.8 \pm 11.1$ & $18.3 \pm 4.5$ & $20.2 \pm 4.0$ \\
\hline Switzerland & $82.7 \pm 22.8$ & $41.5 \pm 16.5$ & $20.0 \pm 5.8$ & $21.2 \pm 4.2$ \\
\hline
\end{tabular}

Abbreviation: Behavioural Pharmaceutical Care Scale.

Total score cannot be computed for the Netherlands, due to a missing item in the referral and consultation activities survey.

\subsection{Factors associated with pharmaceutical care provision}

Thirteen variables were investigated as factors associated with the mean total BPCS scores achieved using combined data from all of the countries surveyed in 2013. Variables that showed a trend of association with the total BPCS score were identified through an initial multiple linear regression model. Significant variables obtained from this model were entered into a final linear regression model. A 10 -variable model was constructed explaining $40 \%$ of the variability of the outcome (total BPCS score). The most influential variable in the model that was positively associated with high total BPCS scores was participation in medication review (Table 6).

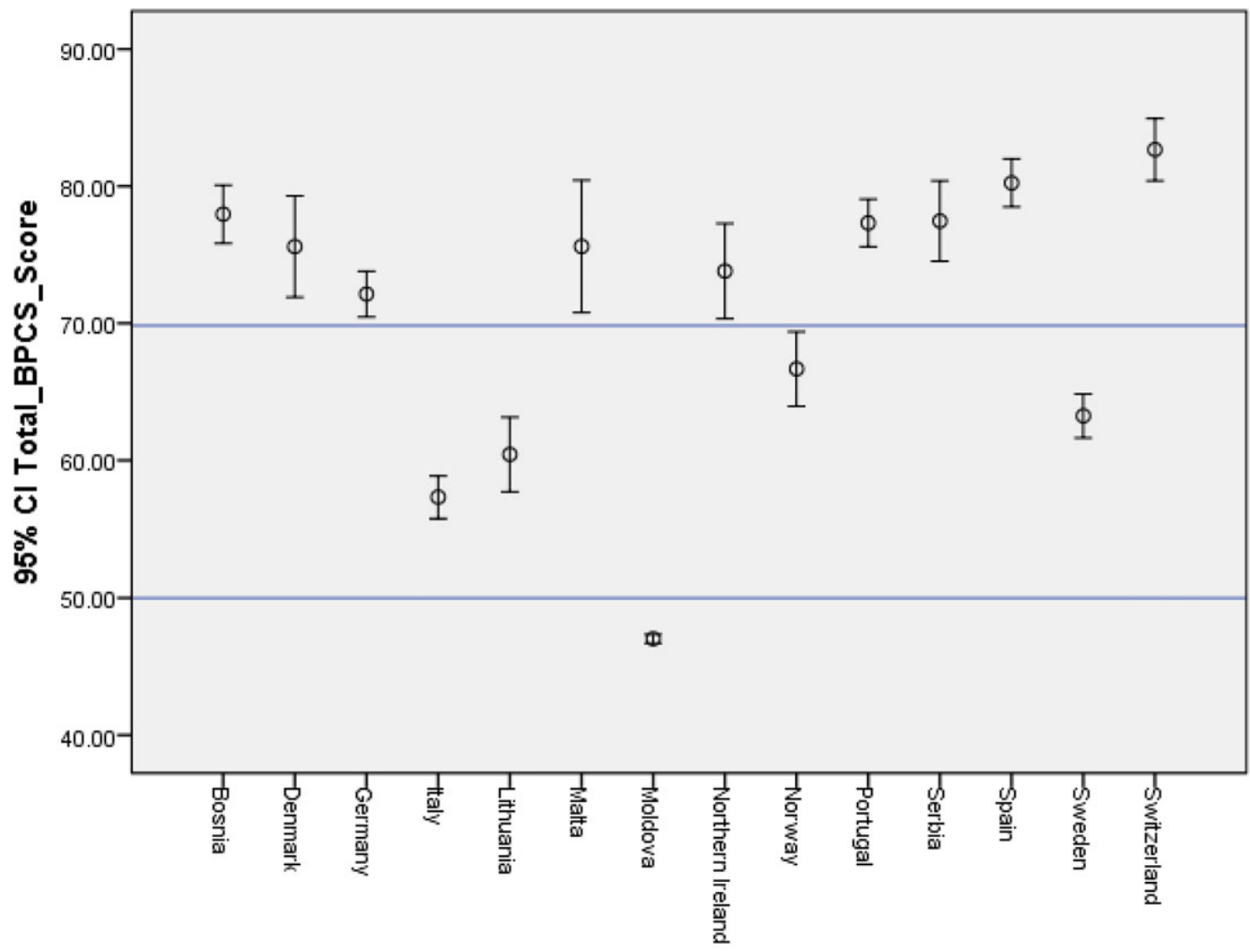

Country of data collection

FIGURE 1 Total score for the modified Behavioural Pharmaceutical Care Scale (BPCS) across different European countries (2013) 


\section{4 | DISCUSSION}

Patient-centred care provision has been proposed as a means to address the challenges of medication-related problems, including ensuring high medication appropriateness and medication adherence to prescribed treatments and associated lifestyle factors. ${ }^{23}$ Pharmaceutical care has been viewed as one of the most important roles of the pharmacist and, when appropriately implemented, has been shown to have a positive impact on patient health outcomes. ${ }^{11}$ The present study assessed the provision of pharmaceutical care by community pharmacists across Europe.

The pharmaceutical care concept has been in place for a considerable time (since early 1990s), and progressive evolution seems to be happening in Europe. Countries that have implemented the concept over a long period are improving. On the other hand, it is clear that countries, which until recently, had more traditional roles are becoming more aware of pharmaceutical care, by their expressed desire to join the research programme and perhaps as a result of both national and international bodies investing in their full integration in Europe. It is worth noting that although the scores for the Eastern Europe countries were quite low, there was considerable variability among them, perhaps as a result of different policy measures being adopted.

\section{1 | Response rate}

The response rate to a questionnaire is an important issue, as a low rate can increase the risk of bias in the answers received. ${ }^{24}$ The response rate varied from $1.6 \%$ in Spain (but since 346 pharmacies participated, the sample exceeded the minimum estimated sample size required) to $99.0 \%$ in Bosnia. The differences in the response rates between countries can be attributed to the different survey distribution methodology used (online, postal, or face-to-face interview) as well as the variable involvement of national organisations able to motivate response. However, more important than the sample size is its representativeness, assessed by how number of responses compares with national data. On this aspect, it should be noted that the presence of selection bias cannot be disregarded for Sweden, judging by the proportion of pharmacists versus prescriptionists among the respondents, compared to their proportions within the community pharmacy work force. In addition, a much lower response rate was achieved in Sweden in the second assessment $(28.4 \%$; 2013$)$ than in the first survey $(70.9 \%$; 2006).

\subsection{Demographics and practice characteristics}

Community pharmacists from most European countries frequently provided additional services and used computer software routinely when dealing with individual patients. Of note, there was a marked increase in the percentage of pharmacies in a number of European countries (N. Ireland, Portugal, Sweden, and Switzerland) having a private consultation area when compared with findings from the 2006 study. ${ }^{10}$ This provides a basis/facilitator for high quality clinical care for patients, which can be seen as a positive advancement from the 2006 study.

\section{3 | Provision of pharmaceutical care}

The present study showed that the mean score for the community pharmacists across the surveyed European countries was 69.3/160 (43.3\%). The total BPCS scores achieved across different European countries ranged from 47.0 (Moldova) to 82.7 (Switzerland). These findings suggest that the provision of pharmaceutical care by community pharmacists still remains limited across Europe. Individual studies across other countries, including the United States, Denmark, Spain, Northwest China, and Jordan, have also highlighted the issue of low provision of pharmaceutical care by community pharmacists. ${ }^{14,16-21}$

Lack of time and resources has repeatedly been found as the main reasons for the lack of provision of comprehensive pharmaceutical care in the community pharmacy setting internationally. 5,6,9,25 Other studies have suggested that lack of commitment among pharmacy practitioners to pharmaceutical care is a major barrier for

TABLE 4 Summary of providers and non-providers of pharmaceutical care across the European countries surveyed (2013)

\begin{tabular}{|c|c|c|c|c|c|}
\hline Country & $\begin{array}{l}\text { Range of } \\
\text { total BPCS } \\
\text { Score }\end{array}$ & $\begin{array}{l}\text { Score Range in Individual } \\
\text { Country for Providers (top } \\
25 \% \text { ) }\end{array}$ & $\begin{array}{l}\% \text { of Providers (top } \\
25 \% \text { ) in Individual } \\
\text { Country }\end{array}$ & $\begin{array}{l}\text { Score Range in Individual Country } \\
\text { for Non-providers (bottom 25\%) }\end{array}$ & $\begin{array}{l}\% \text { of Non-provider (bottom } \\
25 \% \text { ) in Individual Country }\end{array}$ \\
\hline Bosnia & $46-127$ & $106-127$ & 1.0 & $46-66$ & 8.2 \\
\hline Denmark & $52-108$ & $94-108$ & 14.3 & $52-66$ & 24.5 \\
\hline Germany & $22-150$ & $118-150$ & 4.5 & $22-54$ & 22.5 \\
\hline Italy & $15-132$ & $102-132$ & 3.7 & $15-44$ & 31.7 \\
\hline Lithuania & $17-117$ & $92-117$ & 5.7 & $17-42$ & 20.7 \\
\hline Malta & $35-146$ & $118-146$ & 3.6 & $35-62$ & 28.9 \\
\hline Moldova & $41-55$ & $52-55$ & 7.4 & $41-44$ & 30.3 \\
\hline N. Ireland & $33-133$ & $108-133$ & 8.1 & $33-58$ & 19.3 \\
\hline Norway & $23-136$ & 108-136 & 2.9 & $23-51$ & 21.6 \\
\hline Portugal & $30-143$ & $115-143$ & 5.2 & $30-58$ & 19.3 \\
\hline Serbia & $25-158$ & $124-158$ & 5.8 & $25-59$ & 25.7 \\
\hline Spain & $48-123$ & $104-123$ & 8.0 & $48-67$ & 18.5 \\
\hline Sweden & $21-117$ & $93-117$ & 4.3 & $21-45$ & 12.8 \\
\hline Switzerland & $15-136$ & $105-136$ & 17.4 & $15-46$ & 5.9 \\
\hline
\end{tabular}

The Netherlands are not included in the table because the overall score could not be calculated. 
TABLE 5 Comparison of BPCS scores restricted to countries participating in both editions

\begin{tabular}{lccc} 
Country Overall BPCS Score & $\mathbf{2 0 0 6}$ & $\mathbf{2 0 1 3}$ & P Value* \\
\hline Denmark & 50.6 & 75.6 & \\
Germany & 70.8 & 72.1 & \\
Malta & 74.1 & 75.6 & \\
Northern Ireland & 74.0 & 74.1 & \\
\hline Portugal & 76.5 & 77.5 & \\
Sweden & 62.9 & 63.2 & \\
Switzerland & 73.2 & 82.7 & \\
Mean & 68.9 & 74.4 & .0376 \\
\hline
\end{tabular}

Abbreviation: Behavioural Pharmaceutical Care Scale.

*Mann-Whitney test (1-tailed $P$ value).

implementation. ${ }^{8}$ Although not specifically examined in the present study, it is likely that these remain major barriers. In addition, due to the variability between results for individual pharmacies within each country, the present findings indicate a lack of standardized policies and/or procedures for the delivery of pharmaceutical care.

To promote a more patient centred approach to pharmacy practice, a number of motivators for the provision of pharmaceutical care have been put into place in a number of European countries in the period covered by the overall study ${ }^{3}$ (2006-2013). In Northern Ireland, for example, a number of patient-centred services have been commissioned by the nationalized health service, which include a medicines management initiative, repeat prescription scheme, minor ailments scheme, smoking cessation service, and advice to nursing and residential homes (HSC Business Service Organisation web site; http://www.hscbusiness. hscni.net/services/1944.htm). In Portugal, pharmacists have been remunerated for the provision of additional services to patients with diabetes. $^{26}$ A system for the documentation of medication-related problems has been available in all community pharmacies in Sweden. ${ }^{3,13}$ Reimbursement for certain elements of pharmaceutical care has been agreed in the Netherlands, Switzerland, Germany, and in Great Britain. ${ }^{27}$ To promote best practice, the Royal Pharmaceutical Society of Great Britain has launched an early adopter programme that specifically addressed "keeping patients safe when they transfer between care providers" with a focus on medicines management across interfaces. ${ }^{28}$ Such early adopter programmes, in which pioneer pharmacists initially provide and refine new care delivery approaches, promote the application of new care models into routine practice. ${ }^{29}$

However, when compared with the results reported in the 2006 survey, ${ }^{10}$ the mean total BPCS scores improved for several countries. Although differing response rates may have been at least in part responsible for the improvements in some countries, the results seem highly plausible. For instance, in Portugal, the fact that pharmaceutical care has been legally recognized in 2007 cannot be disregarded. ${ }^{30}$ Moreover, in Switzerland, the introduction of remunerated medicines use review in 2010 is very likely to have driven the observed increase. ${ }^{31}$ In Germany, the development of a nationwide service in medication review was launched in 2011; since then, 2 main studies have been rolled out, the Arzneimittelinitiative Sachsen-Thüringen (ARMIN) study, which runs in 2 states and is being remunerated (www.arzneimittelinitiative.de) and the Arzneimitteltherapiesicherheit in Apotheken (ATHINA) study, which currently is still not remunerated. ${ }^{32}$ The sharp increase observed in Denmark also seems consistent with data reported elsewhere, influenced by various ongoing projects. ${ }^{33}$

In general, direct patient care activity scores were higher in the present study, while the referral and consultation activities decreased compared to the 2006 study. The latter finding, if viewed from an optimistic perspective, may be seen as a positive result. The decrease in referral might reflect a more active and independent approach by pharmacists in solving drug-related problems and care issues, perhaps supported by system changes, increased availability of private consultation rooms, and the introduction of a number of recognized remunerated services.

The differences in domain, dimension, and total scores between countries represent heterogeneity in the primary care systems across Europe as well as the lack of harmonized policies and procedures for the delivery of pharmaceutical care. ${ }^{30,34}$ A trend of low provision of patient assessment, documentation activities, implementation of therapeutic objectives and monitoring plans, and direct patient activities overall was noted in the surveyed European countries. This low provision is associated with tasks that are time consuming. The low level of documentation of activities is considered particularly problematic, since in the absence of documentation, follow-up is difficult, ie, without benchmark data and without therapeutic objectives or monitoring plans being recorded. Moreover, lack of documentation will ultimately delay or even be a barrier for successful negotiation

TABLE 6 Final variables included in the linear regression model relating to total Behavioural Pharmaceutical Care Scale score across all European countries surveyed in the current edition

\begin{tabular}{|c|c|c|c|}
\hline Variable & B (Std. Error) & 95.0\% Confidence Interval for B & $P$ Value \\
\hline (Constant) & $47.903(0.586)$ & $46.755-49.051$ & $<.001$ \\
\hline Participation in medication review & $9.901(0.605)$ & 8.716-11.086 & $<.001$ \\
\hline Participation in patient monitoring & $7.663(0.628)$ & $6.432-8.894$ & $<.001$ \\
\hline Routine Participation in local multidisciplinary team meetings & $6.821(0.621)$ & $5.605-8.038$ & $<.001$ \\
\hline Participation in Health promotion/education & $5.333(0.575)$ & $4.206-6.460$ & $<.001$ \\
\hline Having access to clinical data (either through shared database or being easily accessed) & $2.823(0.530)$ & $1.784-3.862$ & $<.001$ \\
\hline Having a postgraduate qualification in pharmacy practice/clinical pharmacy & $2.922(0.639)$ & $1.670-4.174$ & $<.001$ \\
\hline Having a high prescription volume & $0.005(0.001)$ & $0.002-0.007$ & $<.001$ \\
\hline Pharmacy with a private consultation area & $1.787(0.600)$ & $0.611-2.963$ & .003 \\
\hline
\end{tabular}


of remuneration, as evidence of the impact of the service cannot be gathered.

The present study confirmed that a number of pharmaceutical care activities have been implemented into daily practice including screening activities, patient counselling, medication review, verification of patient understanding, and the use of a private area for patient counselling. However, many activities were lacking in countries with less-developed pharmacy systems (eg, Moldova and Lithuania). These findings are in line with the results reported across Europe in 2006 and in the earlier Northern Irish results ${ }^{10,15}$ of 1996.

\section{4 | Providers versus non-providers of pharmaceutical care}

The present study showed that the percentage of respondents who were judged to be providers of pharmaceutical care, using the methodology suggested by Odedina and colleagues $^{14}$ (top 25\% of BPCS scores), was less than those deemed non-providers (bottom $25 \%$ of BPCS scores) in the European countries.

Pharmaceutical care is of course not a service delivered by a pharmacist in isolation from other health care professions. Participation in multidisciplinary meetings can help build professional relationships and help in the initiation of discussions about different patient cases. This type of activity has also been documented as a facilitator to pharmaceutical care, with a particular emphasis on relationships with physicians. ${ }^{9}$ In addition, pharmaceutical care delivery is expected to be enhanced when related services such as health screening, patient monitoring, medication review, and health promotion/education are delivered within the pharmacy. This association was noted in both the present study and the 2006 study. The importance of appropriate software cannot be overemphasized, as this can aid in the decision making and in the documentation of different services. Access to medical notes/clinical information is of paramount importance in the delivery of comprehensive pharmaceutical care, and limited access to patient medical details has been identified by others as a barrier to the provision of pharmaceutical care. ${ }^{25}$ Findings from the present study (having a postgraduate qualification in pharmacy and a high number prescription items dispensed in an average day) were also highlighted as facilitators to pharmaceutical care provision in a US study. ${ }^{16}$ This latter study found that the predictors for pharmaceutical care service provision included pharmacists holding a postgraduate qualification, the pharmacy being located in a clinic, the pharmacy being independent, and a high number of prescriptions dispensed per day. ${ }^{16}$

It should be acknowledged that the slow evolution in the provision of pharmaceutical care is unlikely to change without significant intervention at the system level (eg, new community pharmacy contracts), with adequate remuneration for patient-centred services. Gathering evidence at the national level, coupled with lobbying activities, should be influential in changing policy, ultimately leading to improved practice.

\section{5 | Limitations}

The different survey methodology approaches, coupled with low response rates achieved in a number of countries, represent the major limitation of this study indicating that results may not be generalizable, due to a likely selection bias. Furthermore, the provision of pharmaceutical care was self-reported and self-rated, which may lead to over reporting of good practice initiatives.

\section{5 | CONCLUSIONS}

The present study demonstrated the evolution in self-reported provision of pharmaceutical care by community pharmacists across Europe, as measured by the total BPCS scores. Community pharmacists' provision of pharmaceutical care across Europe was positively associated with participation in additional services (health screening, patient monitoring, medication review, and health promotion/education); participation in multidisciplinary team meetings; routine use of pharmacy software when checking clinical data and drug-drug interactions; access to clinical data (clinical data available through shared database/easily accessed); postgraduate qualifications in pharmacy; working in a pharmacy that has a private patient consultation area; and a high number of prescription items dispensed on an average day. Scores obtained by new European countries suggest they are at a later stage of implementation. The BPCS tool has proven to be useful in detecting changes over time despite the limiting factors. New approaches to enhance recruitment into future surveys, for example, providing a reward for completion, could be used to help encourage a higher uptake, thus avoiding selection bias.

\section{ACKNOWLEDGEMENT}

All national studies were funded locally by the researchers.

\section{CONFLICT OF INTEREST}

The authors declare no conflict of interest.

\section{AUTHOR CONTRIBUTION}

This project was initiated by James McElnay and Tommy Westerlund, and the project delivery team was chaired by James McElnay. The data analysis and initial manuscript were performed by Ghaith Al-Tanni, Ahmed F. Hawwa, Claire Scullin, and James McElnay; the manuscript was finalized by Filipa Alves da Costa, Kurt E Hersberger, and Tommy Westerlund. The other authors were members of the PCNE BPCS Project Team who led the survey in their respective countries.

\section{REFERENCES}

1. Hepler CD, Strand LM. Opportunities and responsibilities in pharmaceutical care. Am J Hosp Pharm. 1990;47(3):533-543.

2. International Pharmaceutical Federation, 2000-last update, FIP statement of policy on good pharmacy education practice [Homepage of International Pharmaceutical Federation], [Online]. Available from: http://www.fip.org/www/uploads/database_file.php?id=188 (accessed 26 January 2013).

3. Farris KB, Fernandez-Llimós F, Benrimoj SI. Pharmaceutical care in community pharmacies: practice and research from around the world. Ann Pharmacother. 2005;39(9):1539-1541.

4. Allemann SS, van Mil JWF, Botermann L, Berger K, Griese N, Hersberger KE. Pharmaceutical Care: the PCNE definition 2013. Int J Clin Pharm. 2014;36(3):544-555. 
5. Van Mil JWF, De Boer WO, Tromp TFJ. European barriers to the implementation of pharmaceutical care. Int $J$ Pharm Pract. 2001;9(3):163-168.

6. Blake KB, Madhavan SS. Perceived barriers to provision of medication therapy management services (MTMS) and the likelihood of a pharmacist to work in a pharmacy that provides MTMS. Ann Pharmacother. 2010;44(3):424-431.

7. Roberts AS, Benrimoj S, Chen TF, Williams KA, Aslani P. Implementing cognitive services in community pharmacy: a review of models and frameworks for change. Int J Pharm Pract. 2006;14(2):105-113.

8. Westerlund LOT, Handl WHA, Marklund BRG, Allebeck P. Pharmacy practitioners' views on computerized documentation of drug-related problems. Ann Pharmacother. 2003;37:354-360.

9. Roberts AS, Benrimoj SI, Chen TF, Williams KA, Aslani P. Practice change in community pharmacy: quantification of facilitators. Ann Pharmacother. 2008;42(6):861-868.

10. Hughes CM, Hawwa AF, Scullin C, et al. Provision of pharmaceutical care by community pharmacists: a comparison across Europe. Pharm World Sci. 2010;32(4):472-487.

11. Roughead EE, Semple SJ, Vitry AI. Pharmaceutical care services: a systematic review of published studies, 1990 to 2003, examining effectiveness in improving patient outcomes. Int J Pharm Pract. 2005;13(1):53-70.

12. Kaes S, Traulsen JM, Søndergaard B, Haugbølle LS. The relevance of political prestudies for implementation studies of cognitive services in community pharmacies. Res Soc Adm Pharm. 2009;5:189-194.

13. Westerlund T, Gelin U, Pettersson E, Skärlund F, Wågström K, Ringbom C. A retrospective analysis of drug-related problems documented in a national database. Int J Pharm Pract. 2013;35(2):202-209.

14. Odedina FT, Segal R. Behavioral pharmaceutical care scale for measuring pharmacists' activities. Am J Health Syst Pharm. 1996;53(8):855-865.

15. Bell HM, McElnay JC, Hughes CM, Woods A. Provision of pharmaceutical care by community pharmacists in Northern Ireland. Am J Health Syst Pharm. 1998;55(19):2009-2013.

16. McDermott JH, Christensen DB. Provision of pharmaceutical care services in North Carolina: a 1999 survey. J Am Pharm Assoc (Washington, DC: 1996). 2002;42(1):26-35.

17. Rossing C, Hansen EH, Krass I. The provision of pharmaceutical care in Denmark: a cross-sectional survey. J Clin Pharm Ther. 2003;28(4):311-318.

18. Rossing C, Hansen EH, Traulsen JM, Krass I. Actual and perceived provision of pharmaceutical care in Danish community pharmacies: the pharmacists' opinions. Pharm World Sci. 2005;27(3):175-181.

19. Zardaín E, Del Valle MO, Loza MI, et al. Psychosocial and behavioural determinants of the implementation of Pharmaceutical Care in Spain. Pharm World Sci. 2009;31(2):174-182.

20. Fang Y, Yang S, Feng B, Ni Y, Zhang K. Pharmacists' perception of pharmaceutical care in community pharmacy: a questionnaire survey in Northwest China. Health Soc Care Community. 2011;19(2):189-197.
21. Aburuz S, Al-Ghazawi M, Snyder A. Pharmaceutical care in a community-based practice setting in Jordan: where are we now with our attitudes and perceived barriers? Int J Pharm Pract. 2012;20(2):71-79.

22. Besterfield DH. Quality Control. Third ed. New Jersey: Prentice Hall; 1990.

23. Kennie-Kaulbach N, Farrell B, Ward N, et al. Pharmacist provision of primary health care: a modified Delphi validation of pharmacists' competencies. BMC Fam Pract. 2012;13:27. https://doi.org/10.1186/ 1471-2296-13-27

24. Edwwards PJ, Roberts IG, Clarke MJ, et al. Methods to increase response rates to postal and electronic questionnaires. Cochrane Database of Systematic Reviews, 2009; 3.

25. Dunlop JA, Shaw JP. Community pharmacists' perspectives on pharmaceutical care implementation in New Zealand. Pharm World Sci. 2002;24(6):224-230.

26. Bulajeva A, Labberton L, Leikola S, et al. Medication review practices in European countries. Res Soc Adm Pharm. 2014;10(5):731-740.

27. van Mil JW, Schulz M, Tromp TF. Pharmaceutical care, European developments in concepts, implementation, teaching, and research: a review. Pharm World Sci. 2004;26(6):303-311.

28. Royal Pharmaceutical Society, 2012. Available from: http://www. rpharms.com/getting-the-medicines-right/early-adopters.asp (accessed 26 November 2016)

29. Posey LM. Proving that pharmaceutical care makes a difference in community pharmacy. J Am Pharm Assoc (Wash). 2003;43(2):136-139.

30. Martins S, van Mil JWF, Costa FA. The organizational framework of community pharmacies in Europe. Int J Clin Pharm. 2015;37(5):896-905

31. Messerli M, Blozik E, Vriends N, Hersberger KE. Impact of a community pharmacist-led medication review on medicines use in patients on polypharmacy-a prospective randomised controlled trial. BMC Health Serv Res. 2016;16(1):145 https://doi.org/10.1186/s12913016-1384-8

32. Seidling HM, Send AF, Bittmann J, et al. Medication review in German community pharmacies-Post-hoc analysis of documented drug-related problems and subsequent interventions in the ATHINA-project. Res Social Adm Pharm. 2016.

33. Søndergaard, B. Implementation of Pharmacy Services in Denmark. FIP, 2015.

34. Van Mil JW, Schulz M. A review of pharmaceutical care in community pharmacy in Europe. Harvard Health Policy Review. 2006;7(1):155-168.

How to cite this article: Costa FA, Scullin C, Al-Taani G, et al. Provision of pharmaceutical care by community pharmacists across Europe: Is it developing and spreading? J Eval Clin Pract. 2017;23:1336-1347. https://doi.org/10.1111/jep.12783 